\title{
WATER STRESS AND HYBRIDIZATION BETWEEN QUERCUS GAMBELII AND QUERCUS GRISEA
}

\author{
Nathan G. Swenson ${ }^{1,2,4}$, Jeanne M. Fair ${ }^{2}$, and Jeff Heikoop 3
}

\begin{abstract}
The historical and environmental forces involved in determining the geographic location of plant hybrid zones have long been of interest. Often hybrid zones appear to be intimately tied to the environment, yet because many abiotic factors covary it is often difficult to understand which are truly the most important in maintaining the position and structure of a hybrid zone. This study uses empirical data and modeling analyses to examine whether abiotic factors are responsible for the location and structure of an oak (Quercus) hybrid zone and, if so, which factors are the most important. Specifically, leaf trait measurements and ecological niche models were used to test the hypothesis that water availability plays a primary role in promoting and maintaining the location of hybridization between 2 species. Leaf trait analyses and ecological niche models both supported the hypothesis that water availability determines the location and structure of the hybrid zone. These findings lend support for the general importance of environmental factors in determining hybrid zone location and structure. Furthermore, they demonstrate how functional trait analyses and predictive ecological niche models can be used in future hybrid zone research.
\end{abstract}

Key words: functional traits, GIS, hybrid zone, specific leaf area, range boundaries, stable isotopes.

The factors that contribute to the formation and location of hybrid zones are of importance to ecologists and evolutionary biologists because of these zones' ability to provide information regarding reproductive isolation between closely related species and ultimately speciation. Due to this importance, a multitude of theories for why and where hybridization occurs exists in the literature. Many of the early mechanisms proposed for the formation of hybrid zones concentrated on the genetic aspects of hybridization (Stebbins 1950, Dobzhansky 1951, Mayr 1963) or the role of species abundances and dispersal abilities (Barton and Hewitt 1985).

In opposition to the classical viewpoint of hybrid zones being independent of the environment, some authors have advocated the importance of preexisting and present-day environmental backdrops in determining the location of hybrid zones (Anderson 1948, 1949, Remington 1968, Endler 1977, Moore 1977, Rieseberg et al. 2003, Swenson 2006). The pioneering work in this area was carried out by the botanist Edgar Anderson, who first presented the idea of "hybridization of the habitat." Anderson $(1948,1949)$ argued that a Louisiana Iris hybrid zone he studied was formed through anthropogenic disruption of the landscape that created intermediate light environments. The introgression that occurred in the Iris system resulted in hybrids that were more fit than either parental species in these intermediate light habitats. Because of this finding, Anderson suggested that plant hybrid zones would tend to cluster in areas that have been recently disturbed by humans. This initial work has been expanded to provide a variety of mechanisms that may explain the correlation between hybrid zones and the environmental backdrop (e.g., Endler 1977, Moore 1977, Buerkle et al. 2000, Rieseberg et al. 2003, Swenson 2006).

Oaks have traditionally caused many problems for taxonomists because oaks often hybridize (Stebbins 1950, Burger 1975). Oak species seem to stay distinct despite high levels of hybridization and introgression (Howard et al. 1997). Further, oaks may display vastly different levels of hybridization at different locations (Williams et al. 2001). The difference in hybridization levels makes oaks an interesting study system in the southwestern United States, where 7 oak (Quercus) species interbreed to form the Quercus undulata hybrid species complex. Quercus gambelii Nutt. has been referred to as the common denominator

\footnotetext{
${ }^{1}$ Department of Biology, New Mexico State University, Las Cruces, NM 88003.

${ }^{2}$ Ecology Group, Division of Risk Reduction and Environmental Stewardship, Los Alamos National Laboratory, Los Alamos, NM 87545.

${ }^{3}$ Hydrology, Geochemistry and Geology Group, Division of Earth and Environmental Sciences, Los Alamos National Laboratory, Los Alamos, NM 87545.

${ }^{4}$ Present address: Department of Ecology and Evolutionary Biology, University of Arizona, Tucson, AZ 85721. E-mail: swenson@email.arizona.edu
} 
in this complex because it seems to be a large component in all hybrids formed, whereas the other 6 species are not always represented (Tucker 1961). While Q. gambelii has been described as being water-stress tolerant when compared to more-northerly distributed Quercus species in North America (Dickson and Tomlinson 1996), it is found in some of the wettest habitats occupied by the 7 species in the Q. undulata complex (Tucker 1961). Conversely, $Q$. grisea is found in some of the driest habitats occupied by species within the $Q$. undulata hybrid complex. This dichotomy has been hypothesized to be important in determining the location of the Q. gambelii-Q. grisea Liebm. hybrid zone (Williams et al. 2001). Williams et al. (2001) showed that pollen inviability in Q. gambelii is responsible for differing levels of hybridization in contact zones and hypothesized that this inviability is due to water stress, but the water-stress hypothesis for the parental species in these contact zones has yet to be tested. Thus, it is unclear whether the location of this hybrid zone is environmentally determined.

During the past 3 decades, plant biologists have become increasingly successful in detecting morphological and physiological responses of plants to water deficit by using leaf trait measurements. Studies describing leaf morphological and physiological traits in parental species and their natural hybrids are now rapidly accumulating (e.g., Williams and Ehleringer 2000, Weih 2001, Fischer et al. 2004, Ludwig et al. 2004, Campbell et al. 2005). Most of these studies have focused on leaf traits that are indicators of plant-water relations, and all of these studies have pointed towards the general importance of the environment in determining the location and structure of plant hybrid zones. In one of the most comprehensive studies to date, Ludwig et al. (2004) analyzed 15 wholeplant traits in the well-studied Helianthus system. They found that approximately half of the traits studied were indeed transgressive, yet not always in the same direction, and they further emphasized the importance of functional traits related to plant-water relations in the hybrid origin of $H$. anomalus.

Although leaf trait measures can be indicative of plant-water relations and can therefore often give strong evidence of plant water-stress tolerance, it can be difficult to conclusively say which abiotic variable (i.e., precipitation or temperature) is the predominate stressor. Ecological niche models have the potential to resolve this problem. Through the use of known parental species or hybrid population locations and digital environmental maps, a multidimensional fundamental ecological niche can be formulated. The relative influence of each digital environmental map used to generate the fundamental niche can then be jackknifed to determine which abiotic variables are the most correlated with species, or hybrid, locations. This attribute of ecological niche models makes them extremely useful to hybrid zone researchers (Kohlmann et al. 1988, Cicero 2004, Swenson 2006, 2008). Furthermore, the combination of ecophysiological measurements, which can indicate environmental determinism of hybrid zone locations, and ecological niche models, which can parse out the importance of individual climatic parameters in determining hybrid zone locations, offers a novel synthetic approach towards determining what controls the location and maintenance of hybrid zones (Swenson 2006, 2008).

Our study uses leaf trait measurements and ecological niche models in a hybrid system to infer whether water availability dictates the location of hybridization between Q. gambelii and Q. grisea in central and northern New Mexico. Specifically, we ask (1) do parental species show differing levels of water stress in areas of differing levels of hybridization? and (2) do hybrid plants use water resources more or less efficiently compared to their parental species?

\section{Methods}

\section{Study Sites}

A total of 3 sites, 2 hybrid zones and 1 contact zone, were utilized for this study. In this study, we defined a hybrid zone as a geographic area where Q. gambelii and Q. grisea interbreed to produce mixed progeny, and we defined a contact zone as a geographic area where no mixed progeny are produced.

The first 2 sites were located at the same elevation in the San Mateo Mountains (SMM) in west central New Mexico $\left(34^{\circ} 56^{\prime} \mathrm{N}\right.$, $\left.107^{\circ} 30^{\prime} \mathrm{W}\right)$. Each of the SMM field sites had an elevation within $100 \mathrm{~m}$ of $2500 \mathrm{~m}$ and were located within approximately $1 \mathrm{~km}$ of each other. One of the 2 SMM sites was determined to be a contact zone because no hybrid 
individuals were evident in the community. The contact zone was located on a slope with a northern aspect and was comprised of trees 3-4 $\mathrm{m}$ in height with few ramets. The other SMM site was determined to be a hybrid zone located on a slope with shallow rocky soils and a southern aspect. The site was comprised of trees 1-2 $\mathrm{m}$ in height, typically with multiple ramets, and with less soil water available as compared to the contact zone described in Williams et al. (2001). Samples from fully expanded sun-exposed leaves from parental plants were taken from both SMM sites. It is important to note that the SMM sites used in this study were the same as those used in the pollen inviability study conducted by Williams et al. (2001), allowing for comparisons between the 2 studies.

The 3rd site was located in Bandelier National Monument (BNM) in north central New Mexico $\left(35^{\circ} 22^{\prime} \mathrm{N}, 106^{\circ} 05^{\prime} \mathrm{W}\right)$ adjacent to the Falls Trail. This site was used to determine whether leaf traits in the natural hybrids in this system are intermediate or transgressive (Rieseberg et al. 1999). This site was determined to be a hybrid zone comprised of shallow rocky soils and trees 1-2 $\mathrm{m}$ in height, typically with multiple ramets. Leaf samples from parental and hybrid plants were collected from within this locality.

Upon collection, samples from all 3 sites were characterized as Q. gambelii, Q. grisea, or an F1 hybrid based on their leaf morphology as described in Aguilar and Boecklen (1992). Plants that appeared to be F2 individuals based on leaf morphology (Aguilar and Boecklen 1992) were not utilized for the study. Leaf morphology has long been recognized as a reliable method for the identification of, and differentiation between, parental species, hybrids, and backcrosses in the Q. undulata complex (Tucker 1961, Howard et al. 1997).

\section{Leaf Trait Measurements}

We collected 30 sun-exposed leaves from 30 individuals of each parental species in the SMM contact zone and also from 30 individual hybrid plants in the SMM and BNM hybrid zones. We used sun-exposed leaves in order to avoid variation in ${ }^{13} \mathrm{C}$ natural abundance ratio $\left({ }^{13} \mathrm{C}\right)$ and nitrogen concentrations of leaf tissue that could be caused by microenvironmental effects (Ehleringer and Cooper 1988). Next, wet leaf area and wet mass were recorded for each individual within 12 hours of collection. Dry mass was recorded after leaf samples were dried for 48 hours in a $60^{\circ} \mathrm{C}$ drying oven. These variables were used to quantify leaf area $\left(\mathrm{cm}^{2}\right.$; LA), leaf succulence (grams of water lost per unit area; LS), and specific leaf area (leaf area per unit mass; SLA). Finally, the leaves from a subset of individuals $(n=10)$ from each species or hybrid population were ground into a fine powder for carbon stable-isotope analysis in order to quantify nitrogen content. Finally, leaves from 10 individuals within each species or hybrid population were ground into a fine powder for carbon stable isotope analysis and in order to quantify their nitrogen content.

Using the $\delta^{13} \mathrm{C}$ data, we then calculated carbon discrimination $\left(\Delta^{13} \mathrm{C}\right)$ values by the following equation:

$$
\Delta^{13} \mathrm{C}=\left(\delta_{\mathrm{a}}-\delta_{\mathrm{p}}\right) /\left(1+\delta_{\mathrm{p}} / 1000\right),
$$

where $\delta_{\mathrm{a}}$ is the natural abundance of ${ }^{13} \mathrm{C}$ of atmospheric carbon dioxide in the ambient environment (estimated as -8.0\% et al. 1993) and $\delta_{p}$ is the natural abundance of ${ }^{13} \mathrm{C}$ in the plant sample. These data were converted to $\Delta^{13} \mathrm{C}$ because of its usefulness as a surrogate for intrinsic water-use efficiency (WUE ${ }_{\mathrm{i}}$; Farquhar et al. 1982, Brugnoli et al. 1988). Intrinsic water-use efficiency, the ratio between net photosynthetic assimilation $(A)$ and stomatal conductance $(\mathrm{g})$, was of interest in this study because it provides information pertaining to plant interaction with the local hydraulic environment (Dawson et al. 2002). Therefore, an increase in the A:g ratio is attributed to a decrease in stomatal conductance. This decrease in $g$ and increase in $\mathrm{WUE}_{\mathrm{i}}$ are of interest in this study because they indicate water stress experienced by the study species and their hybrid.

\section{Ecological Niche Models}

Ecological niche models use known population locations for a species and values for environmental variables (i.e., elevation, precipitation, temperature) at those point locations to quantify the ecological niche for the focal species. This ecological niche is then projected onto a map of a study area. The resulting map represents where the study species, or population, should or could occur based on its modeled niche and the environmental backdrop of the study area. Areas where the species 
is predicted to occur but is known not to occur are therefore indicative of the difference between the fundamental and realized niche of the species, which difference is presumed to be caused by competition or a barrier to dispersal. For all analyses in this study, we used an ecological niche model called the genetic algorithm for rule-set prediction (GARP; Stockwell and Nobel 1992). The desktop version of the GARP software was downloaded from the DesktopGARP home page (www.lifemapper.org/desktopgarp/).

Point location data for Q. gambelii, Q. grisea, and their hybrid were obtained from herbaria at University of Arizona, Arizona State University, and Colorado State University and from personal field collections by the senior author. The physiographic data (elevation, slope, and aspect) used as model input were downloaded from the USGS Seamless Data Distribution System (http://seamless.usgs.gov/). The slope and aspect map layers were derived in a GIS from the digital elevation model (DEM) map layers. The digital map layers of climatic variables were created in a GIS from data provided by the Intergovernmental Panel on Climate Change (www.ipcc.ch/).

GARP randomly sampled from the distribution of known point occurrences and utilized "pseudoabsence" points (areas in the study area where the species has not been recorded) to correlate the known distribution of the species with values for all environmental map layers. This process generated an environmental envelope in which the species have a high probability of occurring. By performing up to 1000 iterations, GARP converged upon a "rule" that described a niche for Q. gambelii, Q. grisea, and their natural hybrids. Using this "rule" GARP projected the niche of each species or their hybrid onto a map of North America to give a predicted range. This process was repeated 100 times for both oak species and their hybrid. Next, we used the portion of the dataset not used for model generation to test the strength of the model output (Stockwell and Nobel 1992, Oberhauser and Peterson 2003). Using a chisquare test for each model, we tested whether the model tended to predict the presence of withheld data points. Specifically we used half of the herbarium point data (data not used to formulate the GARP models) to test whether each model successfully predicted the species' presence in the same locations in our inde- pendent dataset where the species is known to be present. The 80 models with the highest levels of omission error (percentage of independent test points not predicted by the model) were discarded from the 100 replicate niche models. Of the 20 remaining models, 10 were selected as optimal based on their levels of commission error (percentage of predicted area that does not have a known point occurrence). Finally, this subset of 10 optimal models was imported into ArcView 3.2 (ESRI 1999) and overlaid to create one consensus predictive range map.

We determined which environmental factors were the most important in producing accurate models by implementing a 2 nd suite of GARP models for each species and the hybrid. This 2nd modeling process used a subset of environmental map layers while randomly excluding others during the formulation of each model. The jackknifing of environmental layers allowed us to determine which environmental variables were most crucial for accurate models (Peterson and Cohoon 1999). The output from the jackknifing procedure was analyzed using a hierarchical partitioning approach to determine the relative importance of each environmental map layer to a model's predictive accuracy (Chevan and Sutherland 1991, Peterson and Cohoon 1999). Specifically, we quantified how sensitive model output was to a single environmental variable. The variance explained between the jackknifed model and the original model was therefore used to explain the relative contribution of each variable to the generation of the model. The results are reported as 1 - explained variance. In other words, high reported values suggest that the variable was more critical in predicting the distribution of the parental species or hybrid than variables with low reported values were.

\section{RESULTS}

There was a significant difference in mean $\Delta^{13} \mathrm{C}$ values between Q. gambelii individuals in the San Mateo Mountain (SMM) contact zone and those in the hybrid zone (Table 1). Thus, Q. gambelii showed a marked increase in water-use efficiency (WUE) in the hybrid zone compared to the contact zone. The leaf nitrogen $(\% \mathrm{~N})$ was consistent across the different sampling locations (Table 1). Leaf area (LA), specific leaf area (SLA), and leaf succulence 
TABLE 1. The mean trait values for the parental species in the contact zone and hybrid zone in the San Mateo Mountains (SMM) and the results of $t$ tests for intraspecific leaf trait comparisons between the sites.

\begin{tabular}{|c|c|c|c|c|c|c|c|c|}
\hline \multirow[b]{2}{*}{ Trait } & \multicolumn{4}{|c|}{ Quercus gambelii } & \multicolumn{4}{|c|}{ Quercus risea } \\
\hline & $\begin{array}{l}\text { Contact } \\
\text { zone }\end{array}$ & $\begin{array}{l}\text { Hybrid } \\
\text { zone }\end{array}$ & $t$ & $P$ & $\begin{array}{l}\text { Contact } \\
\text { zone }\end{array}$ & $\begin{array}{c}\text { Hybrid } \\
\text { zone }\end{array}$ & $t$ & $P$ \\
\hline$\Delta^{13} \mathrm{C}$ & 16.89 & 15.85 & 7.79 & $<0.05$ & 15.23 & 15.36 & 0.034 & n.s. \\
\hline Leaf $\% \mathrm{~N}$ & 0.92 & 0.91 & 1.34 & n.s. & 1.23 & 1.20 & 1.99 & n.s. \\
\hline Leaf area $\left(\mathrm{cm}^{2}\right)$ & 13.85 & 11.00 & 8.22 & $<0.05$ & 0.75 & 1.20 & 2.01 & n.s. \\
\hline Specific leaf area $\left(\mathrm{cm}^{2} \cdot \mathrm{g}^{-1}\right)$ & 80.14 & 79.52 & 7.23 & $<0.05$ & 77.23 & 65.65 & 1.44 & n.s. \\
\hline Leaf succulence $\left(\mathrm{g} \cdot \mathrm{cm}^{-2}\right)$ & 0.02 & 0.03 & 5.64 & $<0.05$ & 0.03 & 0.01 & 0.05 & n.s. \\
\hline
\end{tabular}

TABLE 2. Comparisons of mean leaf trait values between parental species and hybrids in the Bandelier National Monument (BNM) hybrid zone. We used an ANOVA followed by a Tukey's test to determine which groups differed. Different letters within rows indicate significant difference between groups.

\begin{tabular}{lcccrr}
\hline Trait & Quercus gambelii & Quercus grisea & Hybrid & $F$ & $P$ \\
\hline$\Delta^{13} \mathrm{C}$ & $18.73 \mathrm{a}$ & $16.4 \mathrm{a}$ & $13.94 \mathrm{~b}$ & 4.23 & $<0.05$ \\
Leaf \%N & $0.91 \mathrm{a}$ & $1.18 \mathrm{~b}$ & $1.10 \mathrm{~b}$ & 4.55 & $<0.05$ \\
Leaf Area $\left(\mathrm{cm}^{2}\right)$ & $14.41 \mathrm{a}$ & $1.05 \mathrm{~b}$ & $8.23 \mathrm{c}$ & 5.19 & $<0.05$ \\
Specific Leaf Area $\left(\mathrm{cm}^{2} \cdot \mathrm{g}^{-1}\right)$ & $67.52 \mathrm{a}$ & $78.23 \mathrm{~b}$ & $47.45 \mathrm{c}$ & 4.99 & $<0.05$ \\
Leaf Succulence $\left(\mathrm{g} \cdot \mathrm{cm}^{-2}\right)$ & $0.009 \mathrm{a}$ & $0.02 \mathrm{~b}$ & $0.001 \mathrm{c}$ & 3.13 & $<0.05$ \\
\hline
\end{tabular}

(LS) all decreased significantly when the contact zone was compared to the hybrid zone (Table 1). These results are all indicative of plants responding functionally to water deficit.

The mean $\Delta^{13} \mathrm{C}$ value for $Q$. grisea in the SMM contact zone was not significantly different than that for individuals in the SMM hybrid zone (Table 1). Therefore WUE in $Q$. grisea does not seem to significantly differ in areas with different levels of hybridization. Similar to Q. gambelii, Q. grisea had consistent levels of leaf nitrogen $(\% \mathrm{~N})$ across its different sampling locations (Table 1). LA, SLA, and LS did not show a significant difference between the contact-zone and hybrid-zone Q. grisea populations (Table 1). Thus there was no noticeable functional response of leaves to the different environments experienced between the contact zone and the hybrid zone.

Finally, we examined interspecific relationships in $\mathrm{WUE}_{\mathrm{i}}$ within the contact zone and hybrid zone in the SMM. Inside the contact zone, $Q$. gambelii was significantly greater in $\Delta^{13} \mathrm{C}$ compared to $Q$. grisea; therefore, WUE was higher for $Q$. grisea $(t=3.30, \mathrm{df}=20, P$ $<0.05)$ than it was for $Q$. gambelii. Within the hybrid zone, Q. gambelii had a lower, but not significant, $\Delta^{13} \mathrm{C}$ mean value than $Q$. grisea $\mathrm{did}$ $(t=0.88, \mathrm{df}=20, P>0.05)$.

Within the hybrid zone in Bandelier National Monument (BNM), we sampled leaves from
Q. gambelii, Q. grisea, and their natural hybrid. Quercus gambelii exhibited the highest mean $\Delta^{13} \mathrm{C}$ value, followed by $Q$. grisea and then their hybrid (Table 2). Therefore we can conclude that the hybrid exhibited the highest levels of WUE in the BNM hybrid zone. The SLA and LS of the natural hybrid were significantly lower than those of the parental species (Table 2). LA of the hybrid was also significantly different from LA of the parental species, but the hybrid showed intermediate values (Table 2).

All GARP models produced in this study were found to be statistically significant using a chi-square test $(P<0.05)$. The predictive ecological niche models for $Q$. gambelii, Q. grisea, and their hybrid provided different results (Table 3). The hierarchical partitioning analyses for Q. gambelii showed that precipitation and aspect were the 2 most important variables in determining this species' range. In contrast, temperature and elevation were the 2 most important variables in determining the range of Q. grisea. Finally, precipitation and aspect were the 2 most important abiotic variables in determining hybrid zone location. Thus, while temperature should restrict the range of $Q$. grisea, precipitation should restrict the range of $Q$. gambelii. The predictive range maps are shown in Figs. $1-3$. 
TABLE 3. Hierarchical partitioning results from the GARP jack-knifing procedure, where the values represent the percentage of variation explained by that variable. Large values indicate that the variable is more important than other variables in producing accurate ecological niche models. Similar to a coefficient of determination, the values can be compared across environmental variables and across species, but the significance of the values cannot be discerned. $\mathrm{T}=$ temperature.

\begin{tabular}{lrcrccccc}
\hline & Aspect & Elevation & Slope & Precipitation & Radiation & $\mathrm{T}_{\min }$ & $\mathrm{T}_{\operatorname{mean}}$ & $\mathrm{T}_{\max }$ \\
\hline Quercus gambelii & 24.67 & 2.31 & 3.58 & 62.58 & 2.16 & 2.12 & 1.5 & 1.08 \\
Quercus grisea & 6.57 & 28.61 & 2.86 & 3.68 & 2.12 & 2.11 & 41.95 & 12.1 \\
Hybrid & 25.99 & 2.33 & 10.01 & 52.55 & 2.14 & 1.11 & 1.4 & 4.47 \\
\hline
\end{tabular}

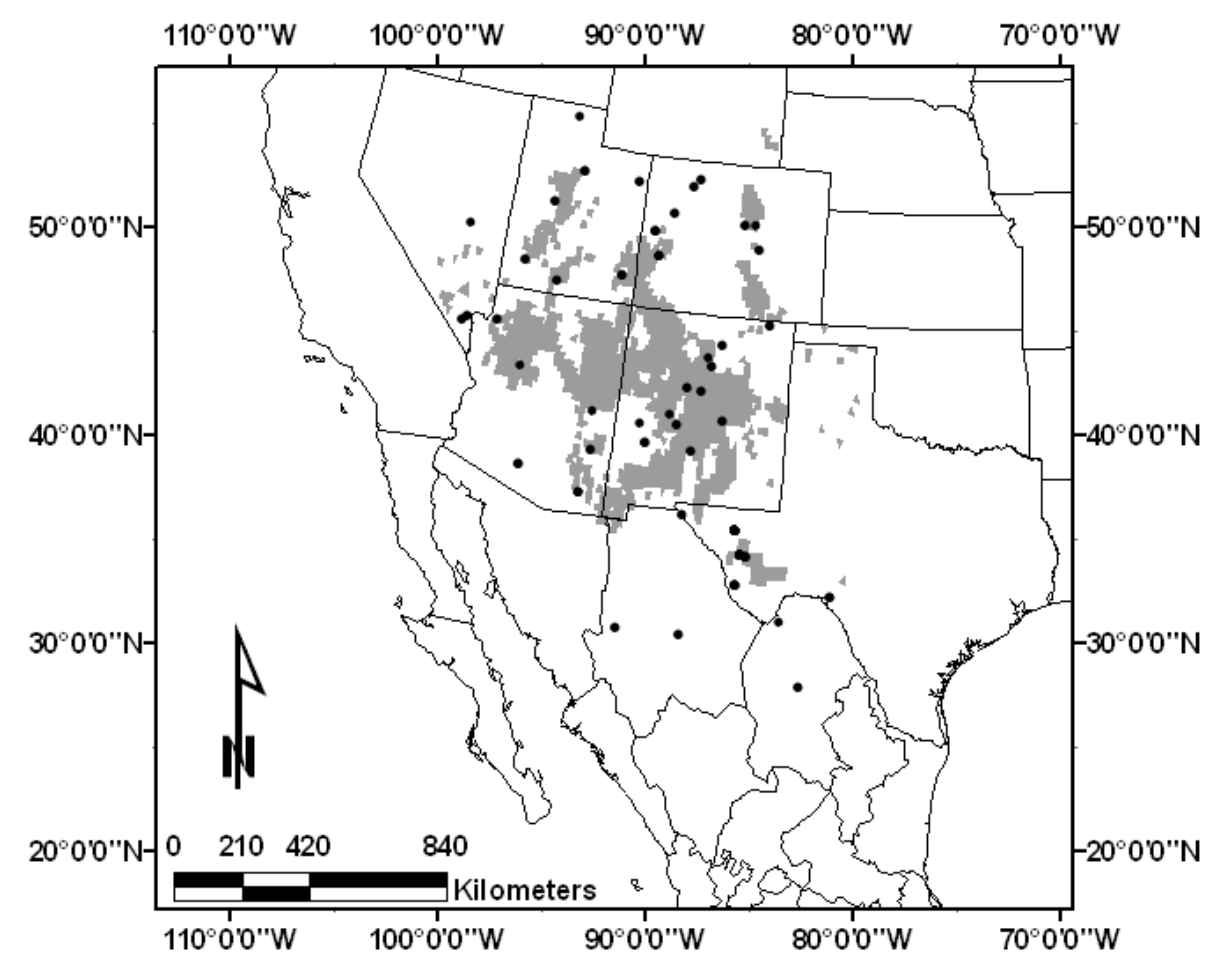

Fig. 1. Predicted range of Quercus gambelii (grey) using GARP niche modeling. The black circles represent herbarium specimen locations. The accuracy of this model was largely determined by the inclusion of aspect and precipitation variables.

\section{Discussion}

Quercus gambelii experienced significantly lower carbon discrimination, and therefore higher levels of water-use efficiency, lower specific leaf area, leaf area, and leaf succulence in the San Mateo Mountain hybrid zone as compared to the San Mateo Mountain contact zone. Converse to these findings, we found no change in foliar nitrogen content across sites with each species. The increase in WUE and the shift in leaf function in the hybrid zone suggest a physiological response in Q. gambelii caused by water deficit. Interestingly, $Q$. grisea did not show a significant change in $\Delta^{13} \mathrm{C}$, SLA, $\mathrm{LA}$, or LS between the contact zone and the hybrid zone. These results suggest that $Q$. grisea did not respond physiologically or morphologically to the abiotic differences between the SMM contact zone and hybrid zone locations.

Results from the Bandelier National Monument (BNM) hybrid zone show that the hybrid has the highest level of WUE, followed by $Q$. gambelii and then by Q. grisea. The hybrid population's $\Delta^{13} \mathrm{C}$, SLA, and LS values were significantly lower than either parental species' values. These results suggest that hybrid individuals tolerate a level of water stress that is higher than the level that either parental species in this hybrid zone can tolerate. The results from the SMM and BNM suggest that Q. gambelii has relatively little ability 


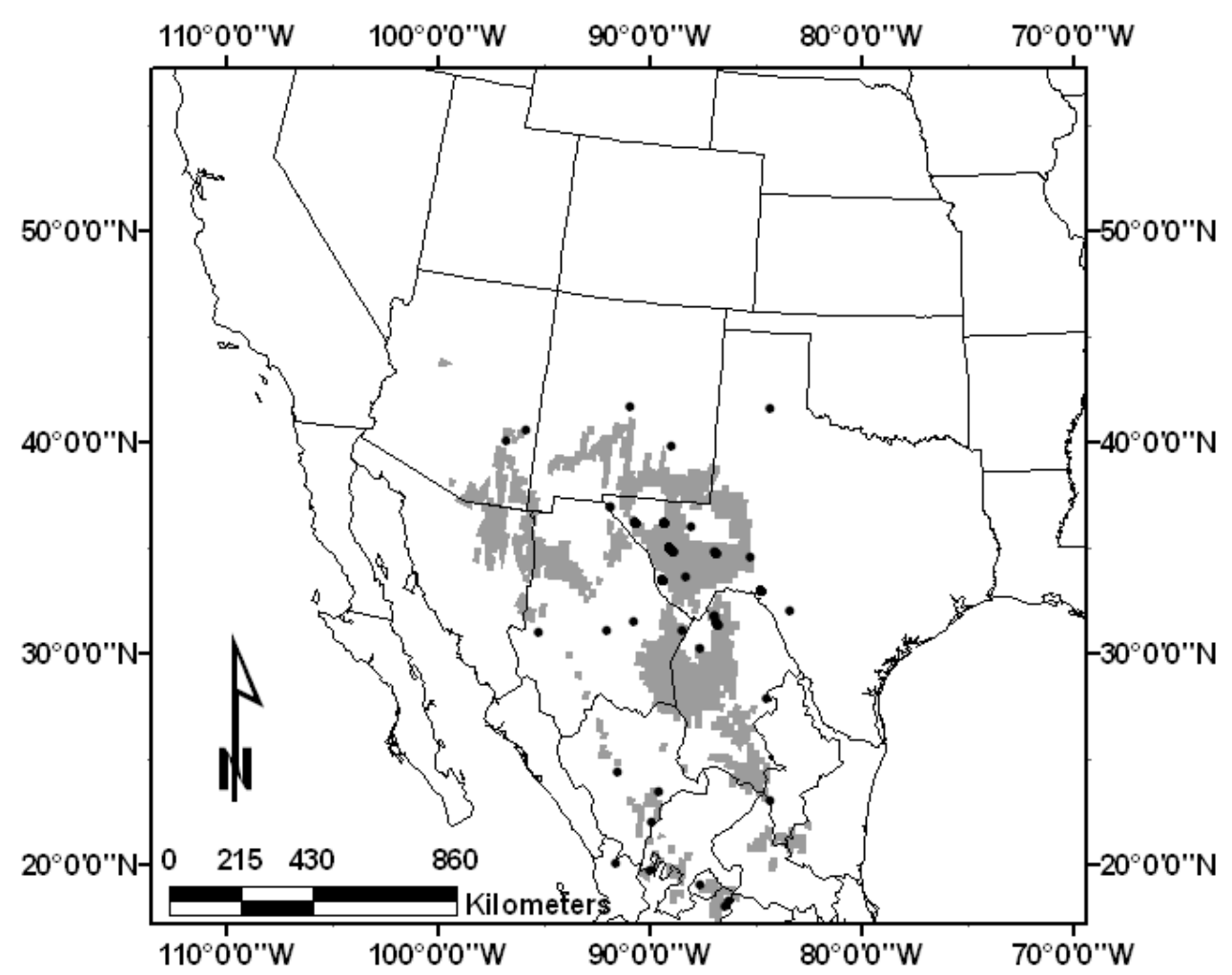

Fig. 2. Predicted range of Quercus grisea (grey) using GARP niche modeling. The black circles represent herbarium specimen locations. The accuracy of this model was largely determined by the inclusion of elevation and mean annual temperature variables.

to tolerate water stress. Further, our results are evidence that $\Delta^{13} \mathrm{C}$, SLA, and LS phenotypes in the natural hybrid individuals in this system are negatively transgressive, whereas LA and foliar nitrogen content values are intermediate. Previous studies have found hybrid LA values to be intermediate between parental values (Ludwig et al. 2004), but, contrary to our findings, $\Delta^{13} \mathrm{C}$, SLA, and LS phenotypes are generally positively transgressive or intermediate (Weih 2001, Fischer et al. 2004, Ludwig et al. 2004). Transgressive traits can be seen as providing a pathway for natural hybrids to colonize novel environments in which selection would favor the hybrid over the parental species (Rieseberg et al. 1999, 2003). The transgressive traits demonstrated in the hybrid in this study all provide increased water-stress tolerance and suggest that the hybrid phenotype may exclude parental genotypes in the driest environments. Further studies in this system will be needed to test whether this is indeed the case.
Although the natural hybrid in this system does seem to be more stress tolerant than the parental species, this evidence is not enough to describe what determines the location of this hybrid zone. The asymmetrical physiological and morphological responses of the parental species to environmental stress seem to be equally if not more informative. The phenotypic shift in Q. gambelii between the SMM hybrid zone and the SMM contact zone indicates that this species is experiencing an increase in water deficit, whereas the Q. grisea phenotypes did not shift noticeably between the 2 locations. Various environmental stresses, including water stress, frequently have negative impacts on plant reproduction (Freeman et al. 1981, Delph et al. 1997, Saini 1997), and it seems plausible that this is occurring in the present hybrid zone (Williams et al. 2001). Although we lack information on the reproductive success of the hybrid individuals, our data show a decrease in water-stress tolerance in one parental species, 


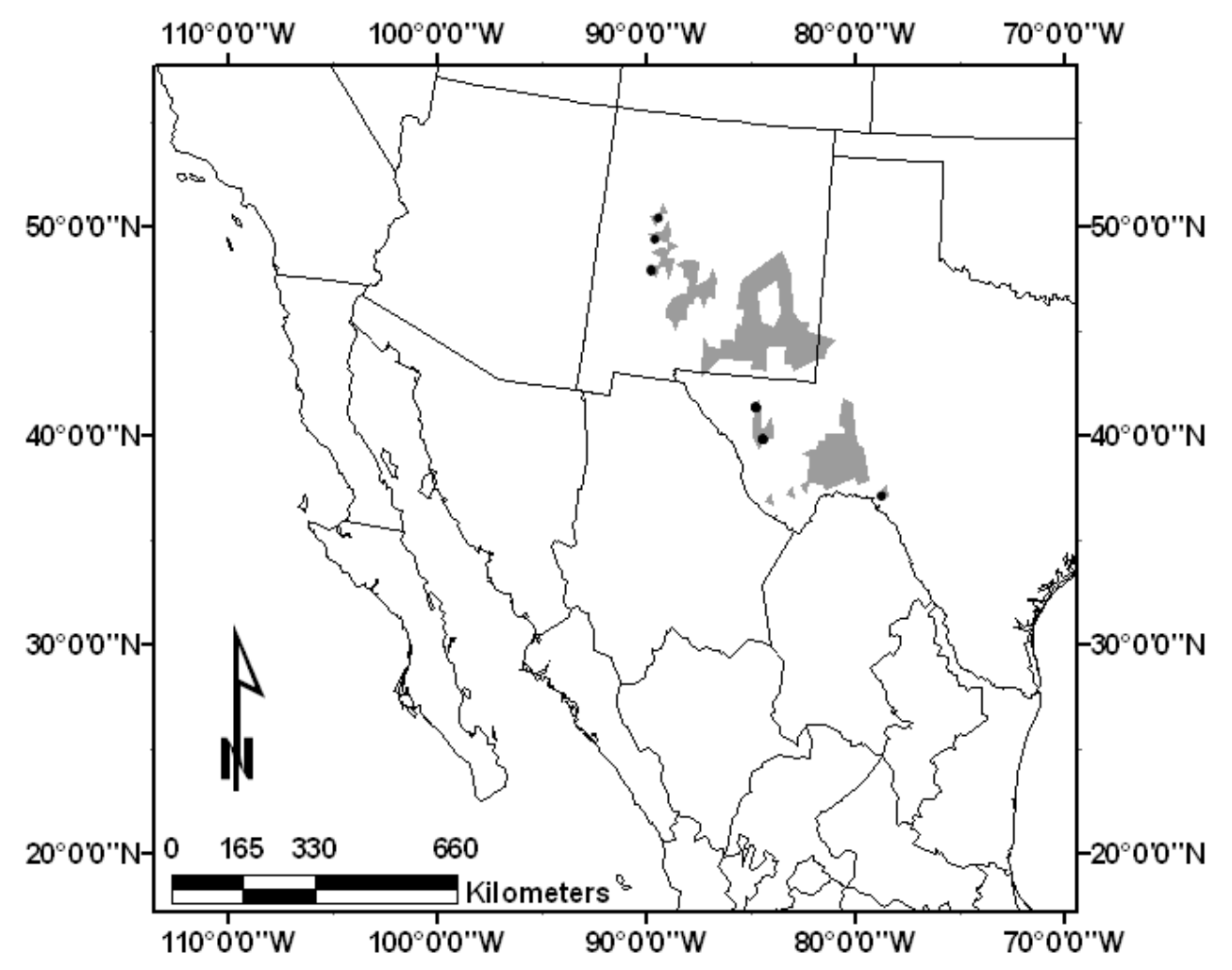

Fig. 3. Predicted range of the Quercus gambelii $\times$ Q. grisea hybrid zone (grey) using GARP niche modeling. The black circles represent herbarium specimen locations and study sites. The accuracy of this model was largely determined by the inclusion of elevation and mean annual temperature variables.

Q. gambelii, where hybridization is common and in the same locations where Williams et al. (2001) demonstrated pollen inviability in $Q$. gambelii. Further studies in this system that measure reproductive success under controlled water availability would prove useful in determining the relative fitness of hybrids compared to parental species.

The physiological and morphological variables of the parental species and their natural hybrid suggest that the environment plays a central role in determining the location of the hybrid zone. Because many interrelated environmental variables (e.g., precipitation and elevation) could potentially explain the physiological and morphological attributes of the plants studied, it is difficult to discern which environmental variables are the most important in determining the location of the hybrid zone. Therefore, we used ecological niche models in this study to uncover the relative importance of different environmental variables that could potentially control the location of the Q. gambelii-Q. grisea hybrid zone. In particular, precipitation and aspect were the 2 most important variables in determining the range of $Q$. gambelii. Because soil water availability is typically correlated with aspect, these results are expected. This suggests that Q. gambelii may be at its physiological limit in the hybrid zone due to a more xeric environment, whereas $Q$. grisea is not at its physiological limit in the contact zone or hybrid zone. According to our model results, Q. grisea should be able to physiologically tolerate a range expansion to higher elevations if it is not competitively excluded by Q. gambelii.

As discussed above, multiple models that include species-by-environment interactions as crucial elements in determining the geographic location of hybrid zones have been proposed (Anderson 1948, 1949, Endler 1977, Moore 1977). On a fine scale, the hybrid zone in question seems dependent on an environmentally 
caused physiological constraint occurring in only one parental species, as hypothesized originally by Williams et al. (2001). Previous studies that have measured environmental parameters in hybrid zones have come to similar conclusions (i.e., that at very fine scales many hybrid zone locations may be controlled by the environment; see Rand and Harrison 1989, Johnston et al. 2001). These observations contrast starkly with the viewpoint held by many early hybrid zone researchers that genetic incompatibilities are the main determinant of hybrid zone locations and that the environment plays little to no role. Through analysis of the anatomy and physiology of the constituent species and their natural hybrid in the present hybrid zone and through sophisticated ecological niche modeling, we have provided support for the alternative viewpoint that the environment does indeed play a large role in determining the location of hybrid zones. It seems that the drought-tolerant transgressive traits exhibited by the natural hybrids in this system are favored in the more xeric environments, which characterize the hybrid zone. In addition our evidence suggests that the drier hybrid zone climate promotes hybridization by inducing water stress and pollen inviability in the less stress-tolerant parental species, Q. gambelii; this is shown by the asymmetrical physiological and morphological responses of the 2 parental species between the contact zone and the hybrid zone.

In summary, it seems likely that other environmentally dependent hybrid zones may also exhibit asymmetrical constraints that play a large role in determining their geographic location and levels of hybridization. These constraints may only be uncovered with multifaceted empirical and theoretical investigations such as our studies. We therefore encourage more fine-scale physiological, morphological, and environmental examinations and ecological niche modeling of hybrid zones.

\section{ACKNOWLEDGMENTS}

We thank Julianna Fessenden-Rahn and Marcey Hess for their assistance in running the isotopic analyses. We also thank Dan Howard, Mike DeMers, and Vince Gutschick for discussions concerning an early version of the manuscript. NGS was supported by a graduate research fellowship from Los Alamos National
Laboratory-New Mexico Experimental Program to Stimulate Competitive Research and also by a grant-in-aid of research from Sigma Xi.

\section{Literature Cited}

Aguilar, F.M., And W.J. Boecklen. 1992. Patterns of herbivory in the Quercus grisea $\times$ Quercus gambelii species complex. Oikos 64:498-504.

Anderson, E. 1948. Hybridization of the habitat. Evolution 2:1-9.

1949. Introgressive hybridization. John Wiley \& Sons, Inc., New York.

Barton, N.H., AND G.M. HewitT. 1985. Analysis of hybrid zones. Annual Review of Ecology and Systematics 16:113-148.

Brugnoli, E., K.T. Hubick, and S. von Caemmerer. 1988. Correlation between the carbon isotope discrimination in leaf starch and sugars of C3 plants and the ratio of intercellular and atmospheric partial pressures of carbon dioxide. Plant Physiology 88:1418-1424.

Buerkle, C.A., R.J. Morris, M.A. Asmussen, and L.H. RIESEBERG. 2000. The likelihood of homoploid hybrid speciation. Heredity 84:441-451.

Burger, W.C. 1975. The species concept in Quercus. Taxon 24:45-50.

Campbell, D.R., C. Galen, and C.A. Wu. 2005. Ecophysiology of first and second generation hybrids in a natural plant hybrid zone. Oecologia 144:214-225.

Chevan, A., AND M. SutherLand. 1991. Hierarchical partitioning. American Statistician 45:90-96.

Cicero, C. 2004. Barriers to sympatry between avian sibling species (Paridae: Baeolophus) in local secondary contact. Evolution 58:1573-1587.

Dawson, T.E., S. Mambelli, A.H. Plamboeck, P.H. TemPLER, AND K.P. TU. 2002. Stable isotopes in plant ecology. Annual Review of Ecology and Systematics 33:507-559.

Delph, L.F., M.H. Johannsson, and A.G. Stephenson. 1997. How environmental factors affect pollen performance: ecological and evolutionary perspectives. Ecology 78:1632-1639.

Dickson, R.E., And P.T. Tomlinson. 1996. Oak growth, development and carbon metabolism in response to water stress. Annals of Forest Science 53:181-196.

Dobzhansky, T. 1951. Genetics and the origin of species. Columbia University Press, New York.

Ehleringer, J.R., AND T.A. CoOper. 1988. Correlations between carbon isotope ratio and microhabitat in desert plants. Oecologia 76:562-566.

Ehleringer, J.R., A.E. Hall, and G.D. Farquhar. 1993. Stable isotopes and plant carbon-water relations. Academic Press, Inc., San Diego, CA.

ENDLER, J.A. 1977. Geographic variation, speciation, and clines. Princeton University Press, Princeton, NJ.

[ESRI] Environmental Systems Research Institute, INC. 1999. ArcView. Version 3.2. Environmental Systems Research Institute, Inc., Redlands, CA.

Farquhar, G.D., M.H. O’Leary, and J.A. Berry. 1982. On the relationship between carbon isotope discrimination and the intercellular carbon dioxide concentration in leaves. Australian Journal of Plant Physiology 11:539-552.

Fischer, D.G., S.C. Hart, T.G. Whitham, G.D. MartinSEN, AND P. KEIM. 2004. Ecosystem implications of 
genetic variation in water-use of a dominant riparian tree. Oecologia 139:288-297.

Freeman, D.C., E.D. McArthur, K.T. Harper, and A.C. BLAUER. 1981. Influence of environment on the floral sex ratio of monoecious plants. Evolution 35:194197.

Howard, D.J., R.W. Preszler, J. Williams, S. Fenchel, AND W.J. Boecklen. 1997. How discrete are oak species? Insights from a hybrid zone between Quercus grisea and Quercus gambelii. Evolution 51:747755 .

Johnston, J.A., R.A. Wesselingh, A.C. Bouck, L.A. DONOVAN, AND M.L. ARNOLD. 2001. Intimately linked or hardly speaking? The relationship between genotype and environmental gradients in a Louisiana Iris hybrid zone. Molecular Ecology 10:673-681.

Kohlmann, B., H. Nix, and D.D. Shaw. 1988. Environmental predictions and distributional limits of chromosomal taxa in the Australian grasshopper Caledia captiva (F.). Oecologia 75:483-493.

Ludwig, F., D.M. Rosenthal, J.A. Johnston, N. Kane, B.L. Gross, C. Lexer, S.A. Dudley, L.H. Rieseberg, AND L.A. Donovan. 2004. Selection on leaf ecophysiological traits in a desert hybrid Helianthus species and early-generation hybrids. Evolution 58:26822692.

Mayr, E. 1963. Animal species and evolution. Harvard University Press, Cambridge, MA.

Moore, W.S. 1977. An evaluation of narrow hybrid zones in vertebrates. Quarterly Review of Biology 52:263277.

Oberhauser, K., And A.T. Peterson. 2003. Modeling current and future potential wintering distributions of eastern North American monarch butterflies. Proceedings of the National Academy of Sciences USA 100:14063-14068

Peterson, A.T., AND K.P. Cohoon. 1999. Sensitivity of distributional prediction algorithms to geographic completeness. Ecological Modelling 117:159-164.

RAND, D.M., AND R.G. HaRRISON. 1989. Ecological genetics of a mosaic hybrid zone: mitrochondrial, nuclear, and reproductive differentiation of crickets by soil type. Evolution 43:432-439.

Remington, C.L. 1968. Suture-zones of hybrid interaction between recently joined biotas. Pages 321-428 in T. Dobzhanski, M.K. Hecht, and W.C. Steere, editors, Evolutionary biology. Plenum Press, New York.
Rieseberg, L.H., M.A. Archer, and R.K. Wayne. 1999. Transgressive segregation, adaptation and speciation. Heredity 83:363-372.

Rieseberg, L.H., O. Raymond, D.M. Rosenthal, Z. Lai, K. Livingston, T. Nakazato, J.L. Durphy, A.E. Schwarzbach, L.A. Donovan, and C. Lexer. 2003. Major ecological transitions facilitated by hybridization. Science 301:1211-1216.

SAINI, H.S. 1997. Effects of water stress on male gametophyte development in plants. Sexual Plant Reproduction 10:67-73.

Stebbins, G.L. 1950. Variation and evolution in plants. Columbia University Press, New York.

Stockwell, D.R.B., AND I.R. Nobel. 1992. Induction of sets of rules from animal distribution data: a robust and informative method of data analysis. Mathematics and Computers in Simulation 32:249-254.

SwEnson, N.G. 2006. GIS-based niche models reveal unifying climatic mechanisms that maintain the location of avian hybrid zone locations in a North American suture zone. Journal of Evolutionary Biology 19:717725 .

. 2008. The past and present influence of geographic information systems on hybrid zone, phylogeographic and speciation research. Journal of Evolutionary Biology 21:421-434.

TuCKER, J.M. 1961. Studies in the Quercus undulata complex. I. A preliminary statement. American Journal of Botany 48:202-208.

WeIH, M. 2001. Evidence for increased sensitivity to nutrient and water stress in a fast-growing hybrid willow compared to a natural willow clone. Tree Physiology 21:1141-1148.

Williams, D.G., and J.R. Ehleringer. 2000. Carbon isotope discrimination and water relations of oak hybrid populations in southwestern Utah. Western North American Naturalist 60:121-129.

Williams, J.H., W.J. Boecklen, and D.J. Howard. 2001. Reproductive processes in two oak (Quercus) contact zones with different levels of hybridization. Heredity 87:680-690.

Received 28 August 2007 Accepted 4 June 2008 